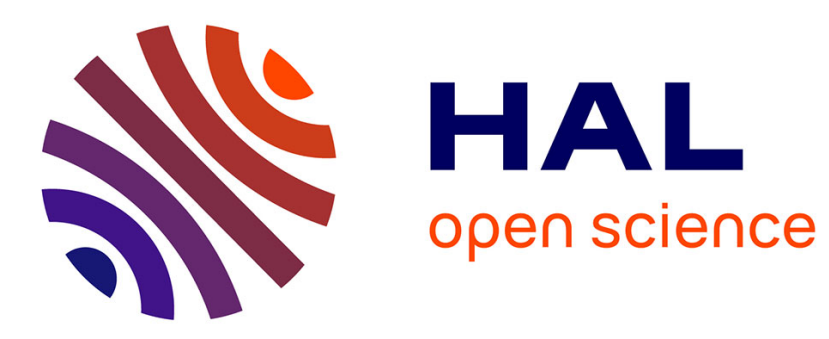

\title{
A simple method for the melt extrusion of cellulose nano-crystal reinforced hydrophobic polymer
}

Kaouther Ben Azouz, Elaine C Ramires, Winke van den Fonteyne, Nadia El Kissi, Alain Dufresne

\section{- To cite this version:}

Kaouther Ben Azouz, Elaine C Ramires, Winke van den Fonteyne, Nadia El Kissi, Alain Dufresne. A simple method for the melt extrusion of cellulose nano-crystal reinforced hydrophobic polymer. ACS Macro Letters, 2011, 1 (1), pp.236-240. 10.1021/mz2001737 . hal-02098618

\section{HAL Id: hal-02098618 https://hal.science/hal-02098618}

Submitted on 12 Apr 2019

HAL is a multi-disciplinary open access archive for the deposit and dissemination of scientific research documents, whether they are published or not. The documents may come from teaching and research institutions in France or abroad, or from public or private research centers.
L'archive ouverte pluridisciplinaire HAL, est destinée au dépôt et à la diffusion de documents scientifiques de niveau recherche, publiés ou non, émanant des établissements d'enseignement et de recherche français ou étrangers, des laboratoires publics ou privés. 


\title{
A simple method for the melt extrusion of cellulose nano- crystal reinforced hydrophobic polymer.
}

\author{
Kaouther Ben Azouz, ${ }^{1}$ Elaine C. Ramires, ${ }^{1 \dagger}$ Winke Van den Fonteyne, ${ }^{1}$ Nadia El Kissi, ${ }^{2}$ and Alain \\ Dufresne ${ }^{1^{*}}$
}

1 Grenoble INP-Pagora, BP 65, 38402 Saint Martin d'Hères Cedex, France

2 Laboratoire de Rhéologie, Grenoble INP-CNRS-UJF, UMR 5520, BP 53, 38041 Grenoble Cedex 9, France

Supporting Information

\begin{abstract}
ABST RACT : The rheological properties of a dispersion of cellulose nanocrystals (CNC) in an aqueous solution of polyoxyethylene (PEO) have been investigated. A peculiar behavior is reported. Upon adding CNC, the viscosity of the suspension first decreases and then increases. Adsorption of PEO chains on the surface of the nanoparticles has been suspected. Freeze-drying of this PEO-adsorbed CNC dispersion was performed and the ensuing lyophilisate was extruded with low density polyethylene. Compared to neat CNC-based nanocomposites, both improved dispersibility and thermal stability were observed. This simple and phys ical method constitutes an approach of choice for the melt processing of CNC-based nanocomposites with a hydrophobic polymeric matrix applicable at industrial scale.
\end{abstract}

Impressive mechanical properties and reinforcing capability, abundance, low weight, renewability and biodegradability make cellulose nanocrystals (CNC) ideal candidates for the processing of polymer nanocomposites. ${ }^{1-4}$ With a Young's modulus of over $100 \mathrm{GPa}$ and a surface area of several hundred $\mathrm{m}^{2} . \mathrm{g}^{-1,5}$ they have the potential to significantly reinforce polymers at low filler loadings. A broad range of potential applications of nanocellulose exists even if a high number of unknown remains at date. Many scientific publications and experts show its potential even if most of the studies focus on their mechanical properties as reinforcing phase and their liquid crystal self-ordering properties. However, as for any nanoparticle, the main challenge is related to their homogeneous dispersion within a polymeric matrix.

CNC are obtained as aqueous suspensions and most investigations focused on hydrosoluble (or at least hydrodispersible) or latex-form polymers.1,3,4 They can be dispersed in non-aqueous media using surfactants or surface chemical grafting involving the high density of surface hydroxyl groups broadening the range of applicable polymeric matrices. However, dispersion in some non-aqueous solvent is possible by a variety of methods (direct dispersion in DMF, low dispersibility in DCM or template approach). ${ }^{6-9}$

However, facilities for industrial-scale CNC production exist and the recent announcement of their large scale production requires the use of more in- dustrial processing techniques. Melt-compounding such as extrusion, commonly used to process thermoplastic polymers, is infrequently employed for the preparation of $\mathrm{CNC}$ reinforced polymer nanocomposites because of inherent incompatibility and thermal stability issues. Indeed, the hydrophilic nature of polysaccharides causes irreversible agglomeration upon drying and aggregation in nonpolar matrices because of the formation of additional hydrogen bonds between the nanoparticles. Moreover, sulfuric acid-prepared CNC present low thermal stability when heated at moderated temperatures, which prevent their processing with methods involving heat.10 This is ascribed to the dehydration reaction resulting from the presence of sulfate groups with negative charge on the surface of CNC. All of these issues limit the processing of CNC-based nanocomposites to wet processing methods such as solution casting, which was extensively studied.

Functionalization of the surface of the nanoparticles is most of the time a necessary step to avoid irreversible agglomeration during drying and aggregation in non-polar matrices. ${ }^{11-13}$ However, this strategy is hardly compatible with an industrial application of these renewable nanoparticles. Therefore, the next challenge is to be able to prepare polymer nanocomposites using industrial processing techniques, thus avoiding the solvent methods and surface chemical modification of the nanoparticles. An attempt to use PVA as compatibilizer to promote the 
dispersion of CNC within the PLA matrix was reported. ${ }^{14}$ Two feeding methods of PVA and CNC were used, dry-mixing with PLA prior extrusion or pumping as suspension directly into the extruder. However, due to immiscibility of the polymers, phase separation occurred. The $\mathrm{CNC}$ were primarily located in the discontinuous PVA phase and only a negligible amount was located in the continuous PLA phase, leading to poor performance of the nanocomposites. Melt processing (extrusion and injection molding) of CNC reinforced PHBV was also attempted. ${ }^{15}$ Despite using low molecular weight polyethylene glycol (PEG) as a compatibilizer, the nanoparticle agglomerates formed during freeze could not be broken and well dispersed by the extrusion process. PEG is miscible with PHBV and a lack of strong interaction between PEG and CNC was suspected. Therefore, during high shear twin-screw compounding PEG could be removed from nanoparticle surface and blended with the PHBV matrix. Without the shielding of the PEG coating, the nanocrystals could not be well dispersed as evidenced from microscopic observations.

In the present paper, we present an easy way to melt process nanocomposite materials from an apolar polymeric matrix (we choose low density polyethylene) and CNC using high molecular weigh polyoxyethylene (PEO).

Figure 1A shows the evolution of both $\mathrm{G}^{\prime}$ and $\mathrm{G}^{\prime \prime}$ moduli obtained within the linear regime, as a function of the angular frequency for the neat PEO solution and $\mathrm{PEO} / \mathrm{CNC}$ suspensions with 3,6 and $9 \mathrm{wt} \%$ cotton nanocrystals. It is worth noting that, as detailed in the Experimental Section, the PEO content was fixed at 1 wt\% on the water basis for all solutions/suspensions and that the CNC content was expressed on the basis of the PEO content. Focusing first on the viscoelastic behavior of the PEO solution it is clear from Figure $1 \mathrm{~A}$ that it is typical of melt polymers with the onset of a terminal zone at low frequency and the beginning of a rubbery plateau at high frequency. It is separated by a G'-G" cross over at intermediate frequency, indicating the transition from a viscous predominant behavior to an elastic predominant one. Figure $1 \mathrm{~B}$ shows a zoom on the experimental values surrounding the cross over zone.
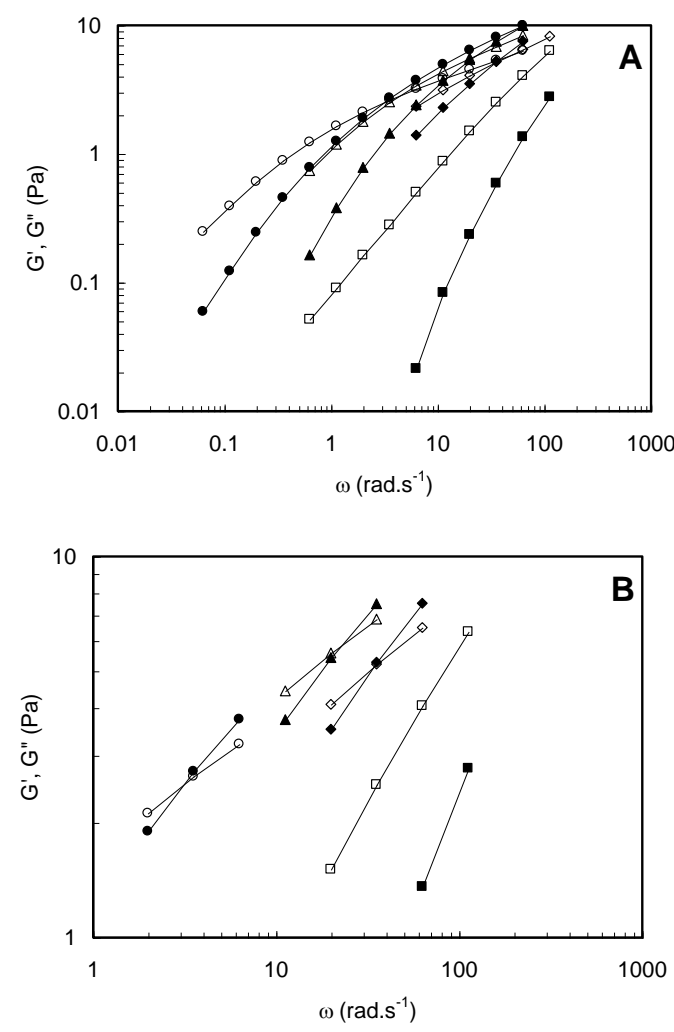

Figure 1. (A) Evolution of the storage (filled symbols) and loss (open symbols) shear moduli within the linear regime for the $1 \mathrm{wt} \%$ PEO $\left(\mathrm{M}_{\mathrm{w}}=5 \times 10^{6}\right.$ g. $\mathrm{mol}^{-1}$ ) solution containing various amounts of $\mathrm{CNC}$ (on the PEO basis) as a function of the frequency: 0 wt\% $(\bullet, O), 3$ wt\% $(\boldsymbol{\Delta}, \Delta), 6$ wt\% $(\boldsymbol{\bullet}, \square)$ and 9 wt\% $(\diamond, \diamond)$. (B) Zoom on the experimental values surrounding the cross over zone.

Considering now the viscoelastic response of the $\mathrm{PEO} / \mathrm{CNC}$ suspensions, the main remark is related to the evolution of the frequency corresponding to the G'-G' cross-over. Except for the PEO solution filled with $6 \mathrm{wt} \% \mathrm{CNC}$ for which the cross over is out of the experimental range, it is clear that it decreases with CNC content, indicating a molecular dynamic that is slowed down for higher CNC concentrations. This is in coherence with what is generally observed for encumbered systems, and may be associated here to the presence of $\mathrm{CNC}$ in the solution. Moreover, a peculiar behavior is observed in Figure 1. A continuous decrease of both $\mathrm{G}^{\prime}$ and $\mathrm{G}^{\prime \prime}$ is observed when increasing the CNC content up to 6 wt\%, and then an increase is reported for the $9 \mathrm{wt} \%$ suspension compared to the $6 \mathrm{wt} \%$ suspension. This peculiar behavior will be explained in the light of steady shear measurements.

In Figure 2A, the steady shear behavior for the neat $1 \mathrm{wt} \%$ PEO solution and with increasing CNC content up to $9 \mathrm{wt} \%$ is represented through the variation of the viscosity as a function of the shear rate. It shows that all solutions/suspensions exhibit a low- 
shear Newtonian viscosity, followed by a shear thinning behavior. Figure $2 \mathrm{~B}$ shows the same data for the neat $1 \mathrm{wt} \%$ PEO solution and solutions containing 3 and 9 wt\% cotton nanocry stals as well as variation of the complex viscosity $\eta^{*}(\omega)$ calculated from $\mathrm{G}^{\prime}$ and $\mathrm{G}^{\prime \prime}$ measurements. It is clear that it superimposes quite well with the steady shear viscosity thus indicating that the Cox-Merz rule ${ }^{16}$ is satisfied for those materials. As for the steady shear behavior (Figure 2A), an unexpected behavior is observed infirming the mechanical strengthen induced by the nanocrystals. Indeed, it is observed that the shear viscosity first decreases when the concentration of nanoparticles increases from o to 6 wt\%. As cotton nanocrystal content still increased (9 wt\%), typical suspension behavior is observed with a viscosity increasing as the concentration increases. However, the viscosity of the $9 \mathrm{wt} \%$ filler PEO solution remains lower than that of the unfilled solution. This peculiar behavior is summarized in Figure 3A which shows the evolution of the viscosity measured for a shear rate of $0.3 \mathrm{~s}^{-1}$ as a function of the cotton nanocrystal content.

Thus, it clearly appears that the viscosity first decreases and this may be attributed to strong affinity between PEO chains and the cellulosic surface through interactions between the oxygen groups of PEO and hydroxyl groups of cellulose. These interactions were characterized in a previous work using heat flow calorimetry. 18 The affinity of water to cellulose surface as a competitive binder was higher, but the polymeric nature of PEO and possibility of wrapping have to be considered. Consequently, increasing nanoparticle content leads to an increase of the available specific area and less free PEO chains are available in the solution. Interactions between CNC are hidden and the behavior is close to that of water. In the present experimental conditions, it appears that a cotton nanocrystal concentration around $6 \mathrm{wt} \%$ corresponds to a critical concentration, sufficient to adsorb all the PEO chains available in the suspension. Obviously, this critical concentration should depend on the specific area of the nanoparticles, i.e. origin of cellulose, and molecular weight of PEO. This aspect is currently under investigation. Above this critical value, the viscosity increases with filler content and the suspension displays a typical suspension behavior with a viscosity increasing with the suspension concentration. However, in the range of nanoparticle concentration investigated the viscosity remains lower than that of the neat PEO solution and its evolution is completely controlled by the viscosity of the nanocrystal suspension in a semi-dilute regime.
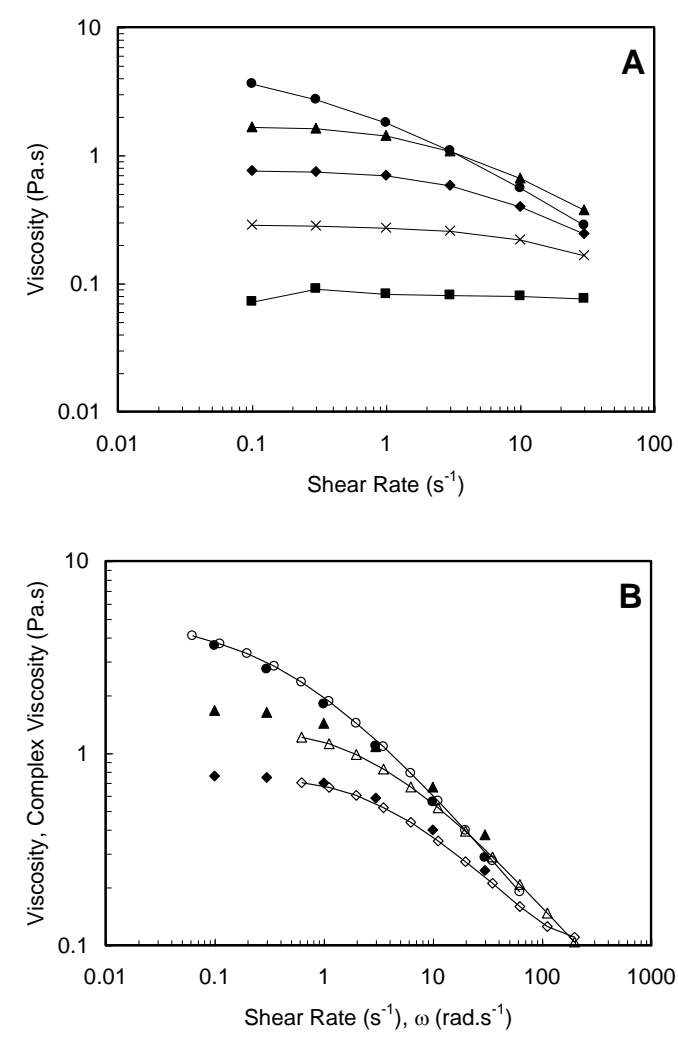

Figure 2. Steady shear viscosity and complex viscosity for the $1 \mathrm{wt} \%$ PEO $\left(\mathrm{M}_{\mathrm{w}}=5 \times 10^{6} \mathrm{~g} \cdot \mathrm{mol}^{-1}\right)$ solution containing various amounts of CNC (on the PEO basis): (A) Evolution of the viscosity as a function of the shear rate, and (B) Evolution of the viscosity as a function of the shear rate (filled symbols) and complex viscosity as a function of the frequency (open symbols): o wt\% $(\bullet, O), 3 \mathrm{wt} \%(\boldsymbol{\Delta}, \Delta), 5 \mathrm{wt} \%$ $(\times), 6 \mathrm{wt} \%(\boldsymbol{\bullet}, \square)$ and $9 \mathrm{wt} \%(\diamond, \diamond)$

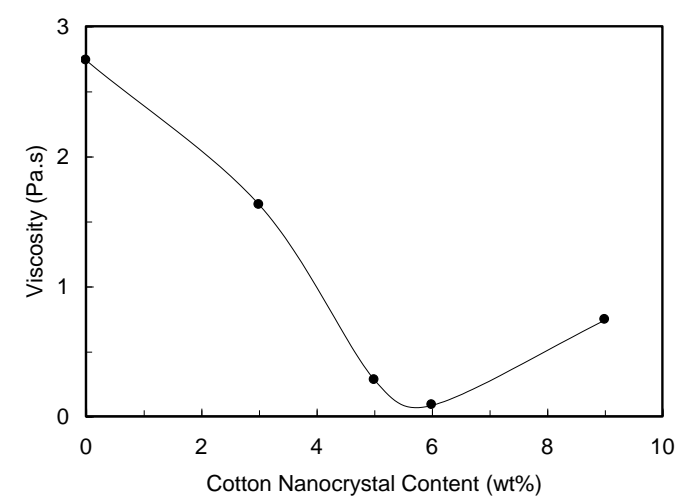

Figure 3. Steady shear viscosity for $1 \mathrm{wt} \% \mathrm{PEO}\left(\mathrm{M}_{\mathrm{w}}\right.$ $\left.=5 \times 10^{6} \mathrm{~g} \cdot \mathrm{mol}^{-1}\right)$ solution as a function of CNC content.

The next step was to know if this localization of the polymer could be retained after freeze-drying and if this wrapping layer could be used to play the role of a compatibilizer with the polyolefin matrix through the ethylene moieties of PEO. Saturation of the cellulosic surface occurs for quite low nanocrystal content compared to the amount of PEO (around 6 
wt\%). It is therefore difficult to use such nanoparticles because the amount of PEO introduced in the composite would be very high. We decided to prepare suspensions consisting of 1 wt\% PEO and 4 wt\% cotton whiskers in water. Therefore, the ratio of cellulose-to-PEO is $80 \mathrm{wt} \%$. It means that only part of the surface of CNC is covered with adsorbed PEO chains.

CNC have been extruded with LDPE to prepare nanocomposite films. Before extrusion the aqueous suspension of cotton nanocrystals with or without PEO was freeze-dried. When PEO was present in the suspension, the freeze-dried material consisted of 20 wt\% PEO and 80 wt\% CNC. The lyophilisates were optically investigated. The freeze-dried material obtained from the mixture of cotton nanocrystals and higher molecular weight PEO $\left(5 \times 10^{6} \mathrm{~g} . \mathrm{mol}^{-}\right.$ 1) forms a dense pad, that tears upon stretching forming very stretchable polymer-like threads. To be able to introduce this lyophilisate into the extruder, it was necessary to chop it into fine pieces. On the contrary, the freeze-dried material obtained from the mixture of cotton nanocrystals and lower molecular weight PEO $\left(3.5 \times 10^{4} \mathrm{~g} \cdot \mathrm{mol}^{-1}\right)$ consists of a very fluffy powder, as for the pure cotton nanocry stal lyophilisate. This difference of appearance is probably ascribed to the possibility of entanglements between long enough adsorbed polymeric chains.

Figure 4 shows the appearance of extruded LDPEbased nanocomposites. The neat LDPE film is obviously translucent as any low thickness polymeric film with a relatively low degree of crystallinity induced by ramifications. When adding $3 \mathrm{wt} \% \mathrm{CNC}$, the film becomes homogeneously dark. This dark coloration of the film after extrusion is an indication of the degradation of the filler, despite the quite low extrusion temperature $\left(160^{\circ} \mathrm{C}\right)$. Cellulose is assumed to degrade at higher temperature, but it is well known that sulfate groups resulting from sulfuric acid hydrolysis treatment decrease the thermal stability of cellulose because of dehydration reaction. ${ }^{10}$ When increasing the $\mathrm{CNC}$ content, it seems that the film is less dark and less homogeneous and becomes dotted with black. These dots probably correspond to nanoparticle aggregate as expected when trying to disperse hydrophilic nanoparticles within a highly hydrophobic matrix.

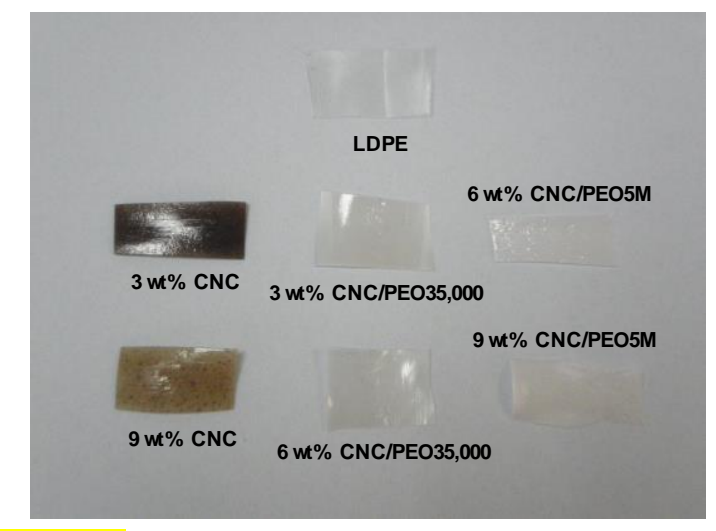

Figure 4. Pictures of the extruded films: unfilled polyethylene (LDPE) matrix, and LDPE reinforced with neat $\mathrm{CNC}$ and PEO-adsorbed CNC.

When using PEO adsorbed-CNC, the appearance of the film becomes similar to the one of the unfilled film, revealing probably a much more homogeneous material. This is a strong indication that the adsorbed polymeric layer probably plays the role of compatibilizer because of the hydrophobic moieties of the monomer unit of PEO. Moreover, the dark color observed for uncompatibilized samples disappears. It could be related to the protection of sulfate groups induced by the coating polymeric layer. Most probably, the use of a high molecular weight PEO is important to achieve this effect. Indeed, previous tests have proved unsuccessful because of the pulling-out of the adsorbed polymer upon extrusion. 15

To access the level of homogeneity of the samples, microscopic observations were carried out on extruded nanocomposites and the thermal stability of the filler was determined from thermogravimetric analy sis (TGA).

Figure 5 shows SEMs of LDPE-based extruded films. The freshly fractured surface of the neat LDPE film (Fig. 5A) is smooth and uniform. For nanocomposites (Figures $5 \mathrm{~B}-\mathrm{D}$ ), a slightly rougher aspect is observed. It is probably due to the brittle fracture under liquid nitrogen. The cellulosic nanoparticles are hardly distinguishable but the presence of nanocrystal aggregates (spotted by arrows) is reported for the uncompatibilized sample (Figure $5 \mathrm{~B}$ ). This aggregation phenomenon is not observed for PEOcompatibilized nanocomposite films. However, the latter shows many air bubbles whose origin is unclear. 

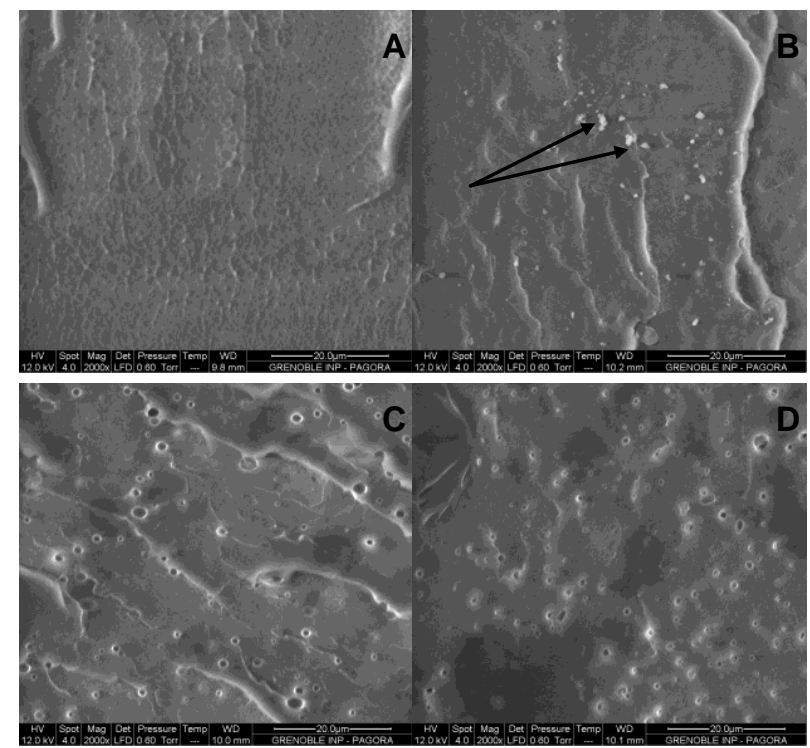

Figure 5. SEMs of (A) neat LDPE, and LDPE reinforced with (B) $9 \mathrm{wt} \% \mathrm{CNC}$, (C) $6 \mathrm{wt} \%$ PEO-adsorbed $\mathrm{CNC}\left(3.5 \times 10^{4} \mathrm{~g}^{\mathrm{mol}} \mathrm{m}^{-1}\right)$, and (D) $9 \mathrm{wt} \%$ PEO-adsorbed $\mathrm{CNC}\left(5 \times 10^{6} \mathrm{~g} \cdot \mathrm{mol}^{-1}\right)$.

TGA experiments were carried out for freeze-dried neat as well as PEO-adsorbed CNC. Results are reported in Figure 6. For neat $\mathrm{CNC}$, an initial weight loss is observed upon heating up to $100^{\circ} \mathrm{C}$. It corresponds to the removal of moisture in the material. At higher temperatures, a gradual weight loss in the range $200-400^{\circ} \mathrm{C}$ is reported. It is well known that small amounts of sulfate groups resulting from the sulphuric acid hydrolysis process induce a considerable decrease in degradation temperatures. ${ }^{10} \mathrm{~A}$ complex behavior was reported, in which the lower temperature degradation process may correspond to the degradation of more accessible and therefore more highly sulfated amorphous regions, whereas the higher temperature process is related to the breakdown of unsulfated crystal. The char fraction was also found to increase upon acid hydrolysis and displayed a continuous increase upon prolonged hydrolysis times. ${ }^{10}$ It was ascribed to the higher amount of sulfated groups acting as flame retardants.

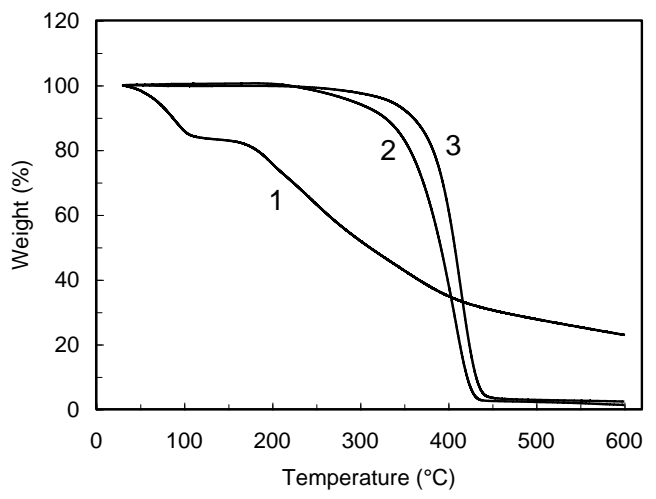

Figure 6. TGA curves of freeze-dried CNC: neat CNC (1) and PEO-adsorbed CNC (CNC:PEO 80:20) with $3.5 \times 10^{4} \mathrm{~g} \cdot \mathrm{mol}^{-1}(2)$, and $5 \times 10^{6} \mathrm{~g} \cdot \mathrm{mol}^{-1}(3)$.

For PEO-CNC mixtures, the thermal degradation behavior is significantly different. No low temperature weight loss is observed, probably because of the less hydrophilic nature of the material. Moreover, the main degradation process is shifted towards higher temperatures and occurs in a narrower temperature range. This effect is enhanced when using the higher molecular weight PEO. This is probably ascribed to a protection role of adsorbed PEO chains that hidden the surface sulfate groups of CNC. It can explain the improved thermal stability and lower thermal degradation of LDPE-based nanocomposites processed from PEO-adsorbed CNC.

This paper reports preliminary results showing the possibility to melt process nanocomposites consisting of cellulose nanocrystals and a hydrophobic polymeric matrix (low density polyethylene in this investigation). The simple and physical method reported in this study avoids the classical solvent methods and surface chemical modification of the nanoparticles. It therefore constitutes an approach applicable at industrial scale. The basic idea consists in wrapping the nanoparticles with a polymer bearing moieties susceptible to interact physically with the cellulosic surface and with the apolar matrix. These interactions were evidenced from rheological measurements performed in aqueous suspensions. It is expected to overcome an important challenge aiming in melt processing this class of nanocomposites. This strategy could also be applied for example to the extrusion of polyvinyl alcohol using PEO as a buffer against degradation. However, further investigation is necessary to fully understand the phenomena involved, and study the role of the specific area of the nanoparticles and molecular weight of the compatibilizing polymer. Moreover, the physical and mechanical characterization of extruded nanocomposite films should be performed. These experiments are in progress.

\section{ASSOCIATED CONTENT}

Supporting Information. Materials, processing of nanocomposites, and experimental techniques. This material is available free of charge via the Internet at http://pubs.acs.org.

\section{AUTHOR INFORMATION}

\section{Corresponding Author}

* E-mail: Alain.Dufresne@pagora.grenoble-inp.fr. 
† Instituto de Química de São Carlos (IQSC),

Univ ersidade de São Paulo (USP), C.P. 780, 13560-97o

São Carlos, Brazil.

\section{REFERENCES}

(1) Azizi Samir, M.A.S.; Alloin, F.; Dufresne. A. Biomacromolecules 2005, 6, 612-626.

(2) Dufresne, A. J. Nanosci. Nanotechnol. 2oo6, 6, $322-330$.

(3) Dufresne, A. Can. J. Chem. 2oo8, 86, 484-494.

(4) Habibi, Y.; Lucia, L.A.; Rojas, O.A. Chem. Rev. 2010, $110,3479-3500$.

(5) Šturcova, A.; Davies, G.R.; Eichhorn, S.J. Biomacromolecules 2005, 6, $1055-1061$.

(6) Azizi Samir, M.A.S.; Alloin, F.; Sanchez, J.Y.; El Kissi, N.; Dufresne, A. Macrom olecules 2004 , 37, $1386-1393$.

(7) van den Berg, O.; Capadona, J.R.; Weder, C. Biom a crom olecules $2007,8,1353^{-1357 .}$.

(8) Capadona, J.R.; Van den Berg, O.; Capadona, L.; Schroeter, M.; Tyler, D.; Rowan, S.J.; Weder, C. Nature Nanotechnology 2007, 2, 765-769.

(9) Capadona, J.R.; Shanmuganathan, K.; Tyler, D.J.; Rowan, S.J.; Weder, C. Science 2008,319 , $1370-1374$.

(10) Roman, M.; Winter, W.T. Biomacromolecules 2004, 5, $1671-1677$.

(11) de Menezes, A.J.; Siqueira, G.; Curvelo, A.A.S.; Dufresne, A. Polymer 2009, 5 0, 4552-4563.

(12) Goffin, A.-L.; Raquez, J.-M.; Duquesne, E.; Siqueira, G.; Habibi, Y.; Du fr esne, A.; Dubois, Ph. Polymer 2011, 5 2, 153 2-1538.

(13) Goffin, A.-L.; Raquez, J.-M.; Duquesne, E.; Siqueira, G.; Habibi, Y.; Dufresne, A.; Dubois, $\mathrm{Ph}$. Biomacromolecules 2011, 12, 2456-2465.

(14) Bondeson, D.; Oksman, K. Composites Part A 2007, 3 8, $2486-2492$.

(15) Jiang, L.; Morelius, E.; Zhang, J.; Wolcott, M.; Holbery, J. J. Compos. Mat. 20o8, 42, 2629 2645 .

(16) Macosko, C.W. Rheology: Principles, Mea surem ents and Applications, Wiley -VCH, 1994.

(17) Bossard, F.; El Kissi, N.; D’Aprea, A.; Alloin, F.; Sanchez, J.-Y.; Dufresne, A. Rheol. Acta 2o10, 49, 529-540.

(18) Azizi Samir, M.A.S.; Alloin, F.; Sanchez, J.Y.; Dufresne, A. Polymer 2004, 45, 4149-4157. 
Table of Contents (TOC)

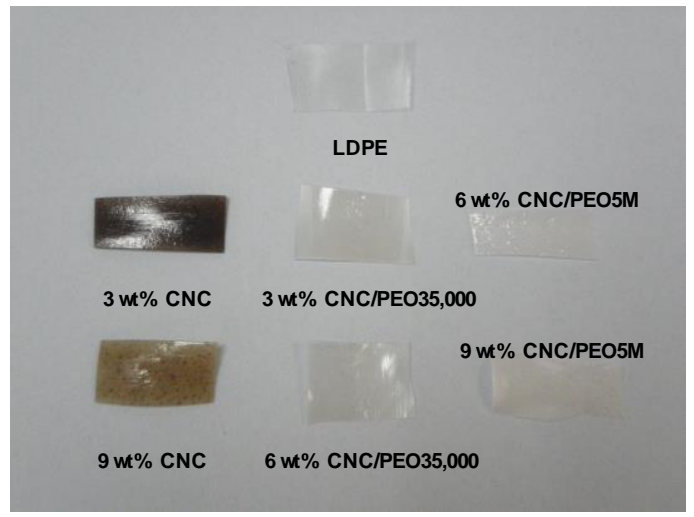

\section{Supporting Information}

\section{A simple method for the melt extrusion of cellulose nanocrystal reinforced hydro-}

\section{phobic polymer}

Kaouther Ben Azouz, ${ }^{1}$ Elaine C. Ramires, ${ }^{1}$ Winke Van den Fonteyne, ${ }^{1}$ Nadia El Kissi, ${ }^{2}$ and Alain Dufresne ${ }^{1 *}$

${ }^{1}$ The International School of Paper, Print Media and Biomaterials (Pagora), Grenoble INP, BP 65, 38402 Saint Martin d'Hères Cedex, France

${ }^{2}$ Laboratoire de Rhéologie, Grenoble INP-CNRS-UJF, UMR 5520, BP 53, 38041 Grenoble Cedex 9, France

* E-mail: Alain.Dufresne@pagora.grenoble-inp.fr 


\section{Experimental Section}

Materials. CNC were prepared from cotton Whatman filter paper. The paper was milled with a laboratory milling device to obtain fine particulate substance. The cotton fibers were extracted in a $2 \mathrm{wt} \%$ aqueous $\mathrm{NaOH}$ solution ( $25 \mathrm{~g}$ fibers for $1 \mathrm{~L}$ solution) for $12 \mathrm{~h}$ at room temperature under mechanical stirring and then filtered and rinsed with distilled water. Acid hydrolysis was achieved at $45^{\circ} \mathrm{C}$ with $65 \mathrm{wt} \%$ sulfuric acid (preheated), for $45 \mathrm{~min}$ under mechanical stirring ( $25 \mathrm{~g}$ fibers for $500 \mathrm{~mL}$ solution). The suspension was diluted with ice cubes to stop the reaction and washed until neutrality by successive centrifugations at $10,000 \mathrm{rpm}$ and $4^{\circ} \mathrm{C}$ for 20 min each step and dialyzed against distilled water. After dialysis, the dispersion of nanocrystals was completed by an ultrasonic treatment using a Branson sonifier, filtered and a few drops of chloroform were added to avoid bacterial growth.

Low density polyethylene (LDPE - Lacqtene $1008 \mathrm{FE} 24$ ) with a density of $0.924 \mathrm{~g} . \mathrm{cm}^{-3}$ and a melting point of $112^{\circ} \mathrm{C}$ was supplied by Atofina S.A. Polyoxyethylene (PEO) with average molecular weights $\mathrm{M}_{\mathrm{w}}=3.5 \times 10^{4}$ and $5 \times 10^{6}$ g.mol ${ }^{-1}$ was purchased from Fluka Chemika and Sigma Aldrich, respectively. Their melting point is around $65^{\circ} \mathrm{C}$.

Processing of Nanocomposites. PEO solutions were prepared by adding $1.25 \%$ of the polymer in distilled water. The solution was protected against light by an aluminum foil and weakly stirred at $500 \mathrm{rpm}$ for 4 days at room temperature. This procedure was shown to avoid degradation of the polymer. ${ }^{16}$ The desired amount of cotton nanocrystals aqueous suspension was added to the solution and stirred for $30 \mathrm{~min}$. The proper amount of distilled water was then added to reach a final PEO concentration in water of $1 \mathrm{wt} \%$ and the suspension was stirred for $1 \mathrm{~h}$. Rheometrical measurements were performed for these suspensions with different amounts of CNC which content was expressed on the basis of the PEO content.

Cotton nanocrystals reinforced LDPE films were prepared by extrusion. First, the CNC suspension with or without PEO was freeze-dried. LDPE and this lyophilisate were introduced in the mixing chamber of a twinscrew DSM Micro 15 compounder and allowed to melt at $160^{\circ} \mathrm{C}$. The mixing speed was $60 \mathrm{rpm}$ for $10 \mathrm{~min} .8$ 
Extrusion was carried out with a slit die of $0.6 \mathrm{~mm}$ in gap and $1 \mathrm{~cm}$ in length. The nanocrystal content ranged between 0 and $9 \mathrm{wt} \%$ (expressed on the basis of the LDPE + PEO content).

\section{Experimental Methods.}

Rheometry Measurements. The rheometrical measurements were performed using a rotational rheometer, the MCR, from Anton Paar. The cone and plate geometry, with a $50 \mathrm{~mm}$ diameter plate and an angle of $1^{\circ}$, was used. This geometry was chosen to allow obtaining accurate data for the low viscosities samples considered in this study. To prevent solvent evaporation during measurements, geometries were enclosed in a solvent trap which saturates the atmosphere. The lower plan was equipped with a Peltier thermoelectric device that insures a controlled temperature, fixed at $20^{\circ} \mathrm{C} \pm 0.1^{\circ} \mathrm{C}$ for this study. Two kinds of rheometrical tests were performed.

First, steady shear measurements consisted in applying a rising shear rate ramp, between $0.1 \mathrm{~s}^{-1}$ and $30 \mathrm{~s}^{-1}$. For a given shear rate, $\dot{\gamma}$, the transient shear viscosity versus time was measured and the steady-state viscosity values $\eta(\dot{\gamma})$ were determined as the limit, on long time scales, of the transient viscosity. The aim of these measurements was to determine the optimal conditions in terms of temperature and shear to process the nanocomposites.

Second, tests consisted in dynamic measurements using small amplitude oscillatory shear deformations. Firstly, the linear viscoelastic regime was determined by carrying out a strain sweep at a fixed frequency. The strain range varies from $0.1 \%$ to $100 \%$. The frequencies used were fixed at 0.1 and $1 \mathrm{~Hz}$. Then, isothermal frequency sweeps were carried out within the linear viscoelastic regime and the elastic and viscous modulus, G' and G", respectively, were measured as a function of the frequency of the oscillations $\omega$. The complex viscosity $\eta^{\star}(\omega)$ was deduced from these measurements. In many cases, this complex viscosity is found to be a good evaluation of the shear viscosity $\eta(\dot{\gamma})$. Moreover, for viscoelastic materials, the empirical Cox-Merz rule is found to work very well. It allows to link $\eta^{*}$ and $\eta$ according to the following relation: 


$$
\eta(\dot{\gamma})=\eta^{*}(\omega) \quad \text { for } \quad \dot{\gamma}=\omega
$$

the shear rate being expressed in $\mathrm{s}^{-1}$ and the frequency in rad. $\mathrm{s}^{-1}$.

For the present study, these frequency sweeps were performed in the range 100-0.01 rad. $\mathrm{s}^{-1} \mathrm{starting}$ from the highest frequencies. By this way, less time is needed to obtain a higher number of data points and thermomechanical degradation of the fluid is minimized. It's worth noting that dynamic measurements using small amplitude oscillatory shear deformations are representative of the behavior of the sample at rest and allows for a characterization that is smooth regarding the internal structure of the fluid when it exists.

Microscopic Observations. An environmental scanning electron microscopy (ESEM) on a Quanta 200 FEI device (Everhart-Thornley Detector was used to investigate the morphology of the extruded nanocomposite films and dispersion of the filler within the matrix. The specimens were frozen under liquid nitrogen before being fractured and coated with gold/palladium. SEM observations of the fractured cross-section were obtained using $10 \mathrm{kV}$ secondary electrons.

Thermogravimetric Analysis (TGA). TGA (STA 6000, Perkin Elmer Instruments model, USA) was carried out to determine the thermal stability of freeze-dried cotton nanocrystals and mixtures of CNC with PEO. Measurements were performed under nitrogen flow of $20 \mathrm{~mL} \cdot \mathrm{min}^{-1}$. The samples were heated from $30^{\circ} \mathrm{C}$ to $600^{\circ} \mathrm{C}$ with a heating rate of $10^{\circ} \mathrm{C} \cdot \mathrm{min}^{-1}$. The sample weight was plotted as a function of temperature for all samples. 